\title{
Transforming the Library Culture into Learning Lab Perspective to Strengthen Its Engagement
}

\author{
Rizal Ardianto $^{1}$, Lien Herlina ${ }^{1}$, Raden Isma Anggraini ${ }^{1}$
}

\author{
${ }^{1}$ School of Business IPB University Indonesia \\ *Corresponding author e-mail: rizalaliahsani@gmail.com
}

\begin{abstract}
A library is a place where learning and sharing takes place. Currently with the technology advancement, library began to be less attractive place to visit. Based on this thought, aims of this study were formulated: 1) mapping community behaviour shifts and changes towards the use of libraries in the VUCA Era; 2) to identify factors and characteristics of the main values of learning lab to improve community engagement; 3 ) designing a library learning model based on learning lab perspective; 4) to analyse supervisialy the impacts of 'Learning Lab' Library over the learning process. This study was conducted in some libraries in Bogor City where diverse population and characteristics distribution exist, it is expected to be able to represent Indonesia. This study uses two major methods, namely, design thinking that is used to identify community learning problems and Delphi method used to verify the results of the library lab-based learning business ideas. In this study, questionnaires were distributed to experts and their inputs used to verify and to improve its concepts, strategies, and impacts. The result showed the introduction of the idea of a learning lab that offers the value of learning activities that can accommodate the learning styles of people who are always changing. The learning lab is expected to be able to support and increase community curiosity and interest in learning and increase their engagement as respons to the new library culture.
\end{abstract}

Keywords-design thinking, engagement, learning lab, library culture, VUCA

\section{INTRODUCTION}

The dynamics of change triggered by technological progress have an impact on the development of human civilization in various aspects of life. This change in community behavior shows that each component needs to harmonize among the times. The shift in community behavior in the era of volatility, uncertainty, complexity, and ambiguity (VUCA) from an industrial society to a smart society with connected lifestyles, has changed the structure of interaction behavior in a fast-paced society. VUCA is now available as a stand-alone environmental factor that enforces the entities in uncertain times, which compels to take action in a precarious situation [9]

The ease and openness of access to knowledge and the abundance of information have changed people's behavior. The change and movement of the rapid development of the world require each individual to learn quickly and understand everything in an instant. This has an impact on the learning process of the community. The demand to

always produce work in a fast time makes people love the instant learning process. This can be seen by people who started to leave books because they were considered to be old learning methods and were not very interesting.

Indonesia ranks second as the country with the highest number of libraries after India, with 164,610 libraries [10]. The number of libraries is more than Russia with 113,440 libraries, and the number is more than China, which reaches 105,831 libraries. This fact can see in Figure 1. Libraries in Indonesia are divided into four groups: the school library, which is the most significant contributor in the library population of 113,541 , followed by public libraries, 6,552 college libraries, and 2,057 special libraries.

A large number of library buildings are still not able to increase community interest in learning. People who want to learn are always hindered by access to the library, so there is no growing interest in education. This is because the number of libraries that have not been evenly reached remote areas. Public library services such as provincial libraries and district

/city libraries are only concentrated in district, city, or provincial capitals [7]. In remote areas, practically, the community does not get adequate literacy services.

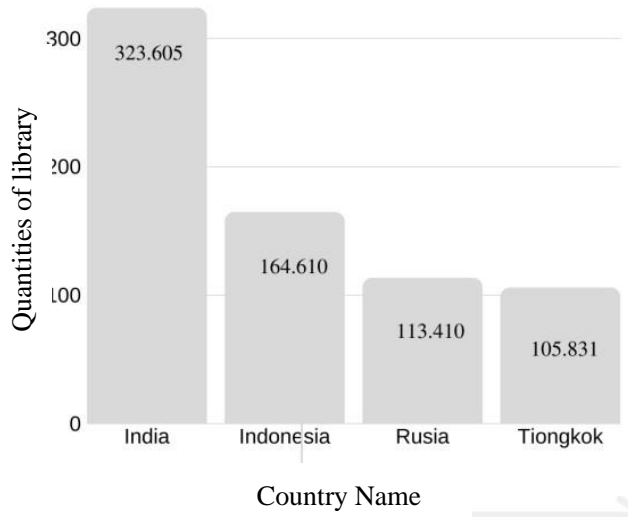

Fig. 1. Countries with the Most Libraries in the World 
Learning lab, which is a continuation of learning laboratory is a research method used to develop productive community partnerships to be able to design a system with behaviors that are responsive to various needs, strengths, and dynamics [2]. Learning is a transformative process in retrieving internalized information and integrating with things that have been experienced by an individual. This condition changes the old understanding that is known or adds knowledge based on what is done. This is based on inputs, processes, and reflections that change one's perspective [3]

Learning is understands the material presented by paying attention to relevant information, rearranging mentally, and relating it to what is already known [4]. Laboratory is a certain place or room and so on equipped with equipment for conducting experiments (investigation and so on) [6]. Laboratory is a place where work activities are carried out to produce something. This place can be a closed room, room, or open space, such as gardens and others [11]. Based on this definition, a laboratory is a place that is used to conduct experiments and training related to physics, biology, and chemistry or other fields of science, which is a closed room, room or open space such as a garden and others. It can be concluded that learning laboratory or learning lab is an ecosystem to integrate learning culture by experimenting in developing science competencies and increasing the skills of an individual's skills which are guided by business concepts. Visitors are parties who are closely involved in the process of understanding something insight so that they are able to connect and create outputs or works from the learning process. In other words, learning lab is a concept in integrating culture in the learning process, the process of experimenting and doing business activities.

The aims of this study were formulated: 1) mapping community behaviour shifts and changes towards the use of libraries in the VUCA Era; 2) to identify factors and characteristics of the main values of learning lab to improve community engagement; 3) designing a library learning model based on learning lab perspective; 4) to analyse supervisialy the impacts of 'Learning Lab' Library over the learning process.

\section{MATERIALS AND METHODS}

The research was conducted in December 2019 until March 2020. The research location was conducted in a library that has national standards in the area. This research was conducted in Bogor, a city with a diverse population distribution and characteristics so that it is expected to represent Indonesia.

In general, this research is a type of descriptive study with survey research techniques on the level of customer comfort on learning activities in the library. A descriptive research method is a method used to analyze data by describing data that has been collected without intending to make conclusions that apply to the public or generalize. Retrieval of library customer perception data through survey techniques.

The data in this study consisted of primary data and secondary data. Primary data is data obtained through observations of the library in Bogor City. Then, interviews with experts consisting of lecturers, librarians, and officials of the relevant offices. Finally, a questionnaire was conducted for 36 respondents to explore information on visitors' problems and test existing solutions. Secondary data

in this study were obtained through literature studies, previous research, data from national libraries, journals, and articles.

\section{A. Design Thinking}

Design thinking is one of the new methods in the design process. Design thinking is a method of solving problems that focus on the customer or user. Process design thinking will produce products that can not only be sold or use the most sophisticated technology. This method combines the needs of users or customers, with the appropriate technological capabilities, and still makes something that can be successful as a business. Design thinking is a method of solving problems that focus on the customer / user. Stages in design thinking are empathize, define, ideate, prototype, and test [5]. Products or applications that are made using the design thinking method, the following steps will be repeated as many times as needed to produce the appropriate product:

\section{1) Empathize}

Empathize is a design thinking approach that emphasizes aspects that exist in user centered design that focuses on the thought process with human values as customers and humanity itself. Empathy becomes the first process in creating an innovation. The design of an innovation will be relevant to human and human values. Therefore, automatically human needs can be met through a solution. When you already know the intended user or customer, then a designer needs to know the experience, emotions, and situation of the customer. This can be done by conducting interviews, and observing the lives of customers.

\section{2) Define}

At this stage, it is pursed to become a point of view. Product or application created. This can be done by making a list of user needs and using knowledge about the conditions that are happening. The defining process helps researchers in the team to gather ideas that are used in the search for ideas related to features, functions, and elements that enable us to solve existing problems. This process has the results of a brief and clear statement of the results of understanding research activities and inspiration.

\section{3) Ideate}

Ideate is the stage of developing ideas or commonly called brainstorming. In this process many ideas emerge that make it possible to be the solution of a problem. All of these ideas are valuable in other words, there are no useless ideas. In this process the brain is forced to be creative by formulating many ideas to get the solutions needed. This can be done by evaluating with the design team by combining the creativity of each designer.

4) Prototype 
Prototype commonly called prototype or archetype in Indonesian is the initial form (example) or standard size of a model. According to the large Indonesian dictionary, the understanding of prototypes is the first form or initial form. Thus, prototypes can be referred to as the initial form created to represent the actual scale before it was developed or even made specifically for development before it was made on the actual scale [1]. Pre-existing ideas need to be implemented in a trial application or product. A real product needs to be produced and possible subscription scenarios.

5) Test

The testing phase cannot be separated from the previous prototype stage. The prototype that has been made is then tested by demonstrating it to the customer. The testing phase has the aim of getting feedback from customers. Testing is the stage to understand customers deeper. Based on customer experience in using trial products, input is obtained to make better products and make improvements to existing products.

\section{B. Lean Canvas}

Lean canvas is an adaptation of the Business Model Canvas (BMC) by Alexander Osterwalder created by Ash Maurya in creating goals for lean (streamlining) and lean startup (quick, concise, and effective startup). Lean canvas offers a business plan that can be followed up and focused on entrepreneurship. Lean canvas is a business model validation tool that is useful for documenting business models, measuring progress, and communicating business to potential users. Lean canvas can be applied to startup businesses and focuses on uncertainty and risk. Maurya explains the elements contained in lean canvas [8]:

\section{1) Problems}

In this element the main problems identified are to be resolved.

\section{2) Solutions}

Solutions are elements used to solve problems that have been identified previously. This element contains a solution that is used to overcome the problem you want to solve.

\section{3) Unique value proposition}

This element explains the unique thing that makes the company different from other competitors' businesses.

\section{4) Unfair advantage}

This element explains the advantages of products or services that make business management of superior products or services far compared to competitors. In this element, it can also be seen that what companies make for competitors is difficult to keep up with business innovation from the company.

\section{5) Key Matrix}

Every business has a measurement that can be used to measure how effectively an activity in the business will work. Measurements on this element serve to measure progress and identify hotspots in the life cycle of visitors or users. This is able to describe the condition of the company that is able to be a reference in making important decisions in the comp

6) Customer segmentation

The customer segment describes a group of people or organizations that are reached and served by the company.

\section{7) Channels}

Channels are ways and containers within a company to be able to communicate with customers in delivering their value proposition. Channels perform several functions, namely increasing customer awareness of the products or services offered by the company, providing value to customers, giving customers the possibility to obtain products or utilize services. Channels can also be used to help customers evaluate product value propositions offered by companies.

8) Cost structure

The cost structure describes all costs expended for business management.

\section{9) Revenue streams}

The revenue flow element describes income from the company's business activities any.

\section{Delphi Method}

The Delphi method is a group process used to conduct surveys and gather opinions on experts in certain fields [12]. Delphi can be characterized as a group method for structuring things with the communication process so that the process becomes effective, it aims to solve complex problems. This method is also used to develop a consensus estimate of the future by asking the opinions of experts, and at the same time eliminating the problem that often occurs namely face to face communication. The Delphi method has been applied in terms of policy making, planning, or ideas that are based on thought or judgment.

\section{RESULTS ANDDISCUSSION}

\section{A. Testing Problems}

Judging from the results of the questionnaire, the general problem of the community in learning is the lack of interest in learning, literacy and learning concepts that have not fulfilled wishes, changes in society and limited access to knowledge in a number of areas. From the results of the questionnaire it can be seen that the lack of learning interest is the most answers from respondents. This is because there are no ecosystems capable of accommodating changes in the way people learn. Various community problems when studying in a library, including: a collection of books and literacy that is incomplete and inadequate, lack of complete carrying capacity of learning facilities (wi-fi, inadequate chairs and tables), it is difficult to find the whereabouts of books and their sources, nuances are boring, sleepy, too quiet, unable to discuss and difficult to access the library. This is a variety of complaints experienced by the community that have been presented through figure three. 


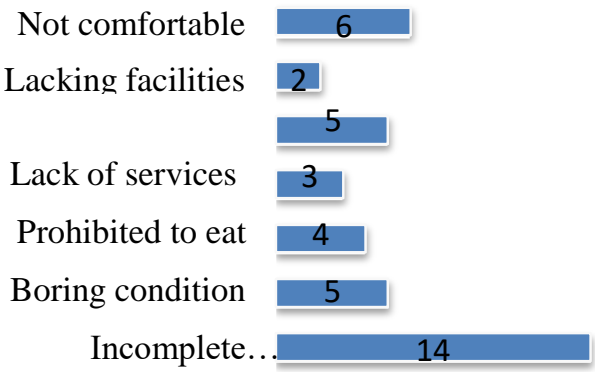

Fig. 2. Learning problems of respondents in the library

In Figure 2 shows the lack of complete literacy and learning materials is the highest reason of the respondent's problem. As many as 11 respondents complained about the limited access or places to eat available in the library. This shifts the old habits of people who study and eat are unusual activities to be carried out together. Inadequate facilities such as internet connectivity are the problems chosen byrespondents, followed by the absence of interesting activities, uncomfortable places, complicated loan systems and less conducive situations. Include from the problems in the library in the community can be grouped into three broad categories namely library infrastructure problems, service systems and the absence of innovative activities (ecosystems).

TABLE 1. GROUPING OF RESPONDENTS PROBLEMS

\begin{tabular}{ll}
\hline \multicolumn{1}{c}{ The Problmes } & Identification and Type of Problems \\
\hline Infrastructure of & - The book and literacy is not enough and \\
Library & update \\
- & The atmosphere is too silent \\
- & Limited places for eat \\
- Incomplete facilities and damaged the & stuff (wifi,chair, tables for study) \\
- The place for discussion room is not & available \\
- Complicated lending book system \\
- Service is not too good enough \\
- Limited access for lend \\
- Activity has not been able to attract and \\
increase learning interest \\
- Sleepy and bored when studying \\
- $\begin{array}{l}\text { No existence of brainstorming and } \\
\text { discussion activities }\end{array}$ \\
- Important source of inspiration
\end{tabular}

Ideate is the stage where researchers try to create ideas and describe the solutions needed by potential users and potential buyers. The ideate must be have include the unique value of learning lab.The unique value or added value that can be given by the learning lab, among others, is connecting people who want to share experiences in titrating, creating a digital platform, the library has a focus space for visitors who need to focus on a quiet atmosphere and discussing space used by visitors to talk with others.

\section{B. Prototype Improvements}

The prototype improvement was based on the responses and suggestions obtained through library visitor respondents and conceptual opinions from the experts which were then implemented using a simulator. Improvements to the interior of the learning lab are done by providing brighter coloring, combining with the concept of light blue, lighting and efficient use of space by maintaining the shape of the building that applies a minimalist concept. The minimalist concept is maintained on the grounds that the concept has been well received by respondents.

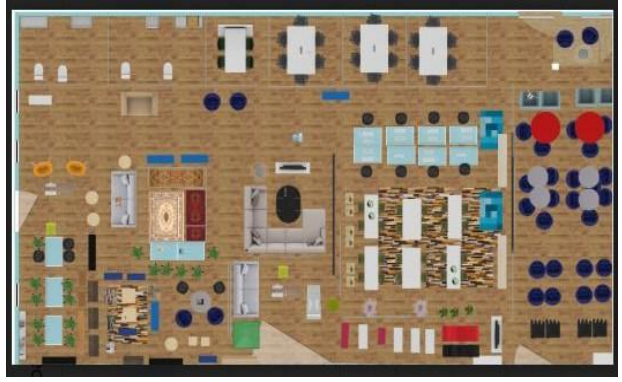

Fig. 3. Prototype Improvement Plan

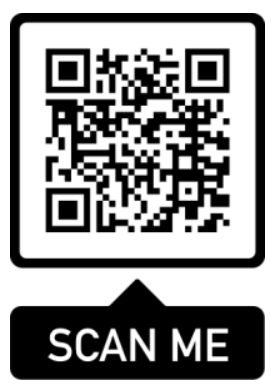

Fig. 4. Video of Prototype Repairement

In Figure 3 is an improvement plan of the prototype and further explanation and the room or other space can be accessed via QR in Figure 4. In Figure 5 is a lobby learning lab. The main room, the communal space in Figure 6 , is a place for discussion, presentation, expressing opinions, and sharing thoughts with other visitors. The focus studying space in Figure 7 is used for visitors who have a high level of focus and need calm in learning. In Figure 8 there is a relax space that is used for relaxing learning, in this room headphones are available to listen to classical music so that learning becomes more relaxed.

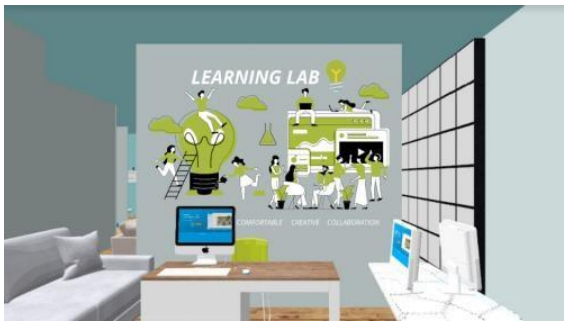

Fig. 5. Lobby of Learning Lab 


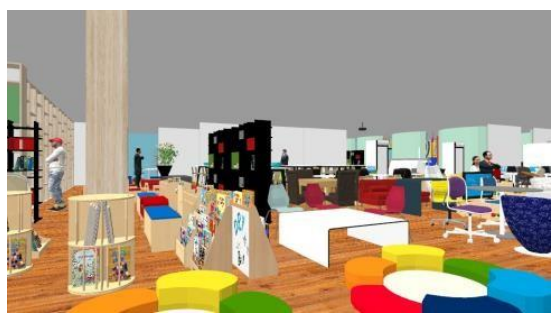

Fig. 6. Communal Space

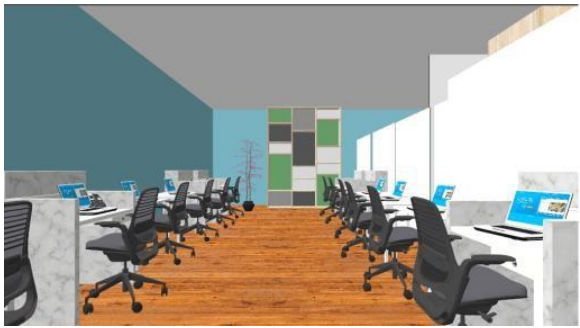

Fig. 7. Focus Studying Space

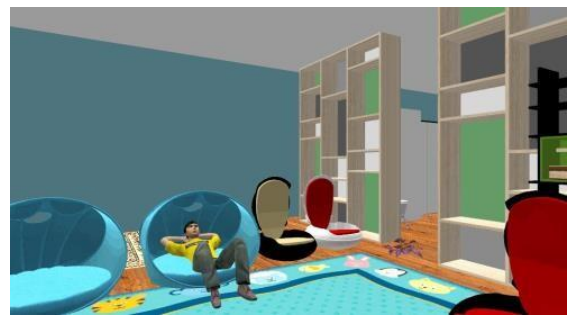

Fig. 8. Relax Space

Not many people know about the importance of applying the concept of learning lab in libraries. It makes learning lab created engagement strategy for the society. This strategy is a blasting team that targets parties and social media groups to campaign for the importance of the learning lab. Awareness of library conditions that require transformation needs to be well understood so that this strategy runs successfully. Bombarding social media is very important to increase community engagement by sending promotional campaigns that are carried out using various methods.

Based on the results of interviews and literature study data, the impact will change learning styles and increase community learning interest. Library visitors will grow and be able to increase comfort in learning through the facilities and activities offered. The level of public awareness of seeking functional literacy will improve and change the community's culture, which is known to be lazy when coming to the library into an intellectual society with broad insight and role in education in Indonesia. In addition, the learning lab also transforms conventional library management into technology-friendly and adaptive control of changes in community behavior that are strictly related to the VUCA era. The library's culture will slowly change, and the cooperative and adaptative nature of the private parties, especially those who manage the library, is needed. However, these impacts cannot occur if carried out by the library itself. There is a need for support and cooperation from all parties, especially the government, through more massive library regulations so that the learning lab's impact is felt by the community optimally.

\section{CONCLUSION}

Learning lab is a concept that transforms cultures in a library, including learning activities and styles. This concept offers a variety of exciting activities and accommodates the way of learning of the community so that it can eliminate the impression of an ancient library and is considered as monumental. Antiquity here means the management of libraries that are still guided by rules that have not adapted the changing times and create images and impressions that libraries are only for reading books. The library seems dominant to accommodate a learning style, namely people who like to read the library have not been able to accommodate literacy materials that update visitors' requests and create a pleasant learning atmosphere with library visitors.

Learning lab-based library will have minimum components namely buildings, facilities, various rooms, activities, and platforms that support library visitors through an ecosystem created to gain knowledge from various sources. These components support each other to create community engagement with the library by building awareness in the community. This will make the library able to adapt to changing times and play an important role in increasing learning and interest in public literacy.

\section{VI.RECOMENDATION}

This research is limited to the concept and design of the learning lab system and library management sustainability strategy. In this research has not reviewed the financial projections needed to create a learning lab library. Financial analysis was not conducted in this study because one study was needed to discuss specifically about financial and financial valuations. So that it gets optimal results. The usefulness of financial analysis can be used as an additional study in the formulation of the learning lab concept so that this business concept is more comprehensive. In addition, the learning lab library can be developed with the segmentation of children to introduce interest in reading and iterating early on. In this connection, a special design and concept about the library is needed that attracts children to play and learn.

Research and study development is needed for various types of specialized libraries that will adapt the learning lab concept. Special libraries have special functions that differ from one library to another. This research emphasizes the cooperation of parties involved in the formation and management of a learning lab based library, namely academics, business, government and community actors so that the execution of this business concept can be carried out sustainably.

\section{ACKNOWLEDGMENT}

We thank to School of Business IPB University and all the faculty member for the opportunity that has been given. 


\section{REFERENCES}

[1] Azis A, Dirgahayu T. 2015. Development of e-office models and prototype of higher education institutions in Indonesia. Journal of Informatics. 3 (3): 129-142.

[2] Bal A, Schrader EM, Afacan K, Mawene D. 2016. Using learning labs for culturally responsive positive behavioral interventions and supports: intervention in school and clinic. Sage Journals. 52 (2). 122-128. doi: 10.1177 / 1053451216636057

[3] Bingham T, Conner M. 2015. The New Social Learning, 2nd Edition: Connect.Collaborate. Work Alexandria (US): Association for Talent Development.

[4] Clark RC, Mayer RE. 2014. E-Learning and the Science of Instruction: Proven Guidelines for Consumers and Designers of Multimedia Learning. New Jersey (US): John Wiley \& Sons, Inc., Hoboken.

[5] Ford C. 2010. An Introduction to Design Thinking - Process Guide. California (US): Institute of Design at Stanford, Standford.

[6] [KBBI] Large Indonesian Dictionary.

[internet] kbbi.kemdikbud.go.id/entri/laboratorium

[7] [Kemendikbud] Ministry of Education and Culture. 2019. Literacy Activity Index Reading 34 Provinces. Jakarta (ID): Education and Culture Policy Research Center, Research and Development Agency, Ministry of Education and Culture.

[8] Maurya A. 2012. Running Lean: Iterate From Plan A to a Plan That Works (Second Edition). Sebastopol, California (US): O'Reilly

[9] Potsangbam C. 2017. Adaptive Performance In VUCA Era - Where is Research Going? International Journal of Management (IJM). 8(6): 99- 108.

[10] [Perpusnas] Perpustakaan Nasional Republik Indonesia. 2018. Jumlah Perpustakaan di Dunia[online] https://www.perpusnas.go.id/ [accessed 24 October 2019]

[11] Sukarso. 2005. Definition and Function of Laboratory. Bandung (ID): Alfabeta.

[12] Yousuf M I. 2007. Using experts opinions through delphi technique. Journal of Practical Assessment, Research and Evaluation. 12(4):1-8 